\title{
Lipophilicity and click reactivity determine the performance of bioorthogonal tetrazine tools in pretargeted in vivo chemistry
}

E. Johanna L. Stéen ${ }^{\dagger, \nexists, \bar{T}}$, Jesper T. Jørgensen ${ }^{\ddagger \neq, \bar{T}}$, Christoph Denk ${ }^{\uparrow, \bar{T}}$, Umberto M. Battisti ${ }^{\dagger}$, Kamilla

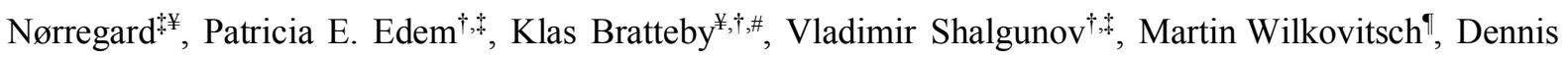
Svatunek ${ }^{\llbracket}$, Christian B. M. Poulie ${ }^{\dagger, \uparrow}$, Lars Hvass ${ }^{\ddagger}$, Marina Simón ${ }^{\ddagger \neq, \bar{\tau}}$, Thomas Wanek ${ }^{\S}$, Raffaella Rossin", Marc Robillard", Jesper L. Kristensen ${ }^{\dagger}$, Hannes Mikula ${ }^{\mathrm{q}, *}$, Andreas Kjaer, ${ }^{\ddagger, *}$ and Matthias M. Herth ${ }^{\dagger, *, *}$ ${ }^{\dagger}$ Department of Drug Design and Pharmacology, Faculty of Health and Medical Sciences, University of Copenhagen, Universitetsparken 2, 2100 Copenhagen, Denmark.

${ }^{\sharp}$ Department of Clinical Physiology, Nuclear Medicine \& PET, Rigshospitalet, Blegdamsvej 9, 2100 Copenhagen, Denmark.

${ }^{\ddagger}$ Cluster for Molecular Imaging, Department of Biomedical Sciences, University of Copenhagen, Blegdamsvej 3, 2100 Copenhagen $\varnothing$, Denmark.

\# Department of Radiation Physics, Skåne University Hospital, Barngatan 3, 22242 Lund, Sweden

${ }_{\S}$ Preclinical Molecular Imaging, AIT Austrian Institute of Technology GmbH, 2444 Seibersdorf, Austria

IInstitute of Applied Synthetic Chemistry, Technische Universität Wien (TU Wien), Getreidemarkt 9, 1060 Vienna, Austria.

"Tagworks Pharmaceuticals, Geert Grooteplein 10, 6525 GA Nijmegen, Netherlands.

\section{ABSTRACT}

The development of highly selective and fast biocompatible reactions for ligation and cleavage has paved the way for new diagnostic and therapeutic applications of in vivo chemistry. The concept of bioorthogonal pretargeting has attracted considerable interest, in particular for the targeted delivery of radionuclides and drugs. In nuclear medicine, pretargeting can provide increased target-to-background ratios at early time-points compared to traditional approaches. This reduces the radiation burden to healthy tissue and, depending on the selected radionuclide, enables better imaging contrast or higher therapeutic efficiency. Moreover, bioorthogonally triggered cleavage of pretargeted antibody-drug conjugates represents an emerging strategy to achieve controlled release and locally increased drug concentrations. The toolbox of bioorthogonal reactions has significantly expanded in the past decade, with the tetrazine ligation being the fastest and one of the most versatile in vivo chemistries. Progress in the field, however, relies heavily on the development and evaluation of (radio)labeled compounds, preventing the use of compound libraries for systematic studies. The rational design of tetrazine probes and triggers has thus been impeded by the limited understanding of the impact of structural parameters on the in vivo ligation performance. In this work, we describe the development of a pretargeted blocking assay that allows for the investigation of the in vivo fate of a structurally diverse library of 45 unlabeled tetrazines and their capability to reach and react with pretargeted trans-cyclooctene (TCO)tagged antibodies in tumor-bearing mice. This study enabled us to assess the correlation of click reactivity and lipophilicity of tetrazines with their in vivo performance. In particular, 
high rate constants $\left(>50,000 \mathrm{M}^{-1} \mathrm{~s}^{-1}\right)$ for the reaction with TCO and low calculated $\log D_{7.4}$ values (below -3) of the tetrazine were identified as strong indicators for successful pretargeted in vivo click chemistry. Click-radiolabeling gave access to a set of selected ${ }^{18} \mathrm{~F}$ labeled tetrazines, including highly reactive scaffolds, which were used in pretargeted PET imaging studies to confirm the results from the blocking study. These insights thus enable the rational design of tetrazine probes for in vivo application and will thereby assist the clinical translation of bioorthogonal pretargeting.

Keywords: bioorthogonal chemistry, tetrazine ligation, pretargeted imaging, PET, fluorine18, molecular imaging

\section{INTRODUCTION}

The concept of in vivo chemistry based on the development of bioorthogonal reactions has led to a renaissance of pretargeting strategies in nuclear medicine and for controlled drug delivery. ${ }^{1-4}$ Monoclonal antibodies (mAbs) have found wide-spread application in this regard, particularly as selective targeting vectors for specific antigens expressed on cancer cells. ${ }^{5}$ For example, immuno-positron emission tomography (PET) can be used for precision medicine, i.e., to guide the selection of patients, who show the highest probability to benefit from a specific therapy. ${ }^{6,7}$ Similarly, radioimmunotherapy (RIT) is based on the application of the unique targeting ability of mAbs to deliver therapeutic radionuclides to diseased tissue, most often to tumors. ${ }^{8}$ RIT has several advantages over conventional external radiation therapy, notably the ability to target and treat the entire tumor burden, including micrometastases. ${ }^{8}$ However, due to the long blood circulation time of mAbs (several days to weeks), adequate tumor-to-background ratios are usually not achieved until 2-4 days after administration, requiring the use of long-lived radionuclides. Most often, this results in a relatively high radiation burden to the patient. ${ }^{9,10}$ In order to reduce the absorbed radiation dose and reach higher tumor-to-background ratios at earlier time points, pretargeting has emerged as an efficient strategy, enabling in vivo radiolabeling of mAbs upon accumulation at their target. $^{2,10-16}$ This is realized by modifying the mAb with a specific reactive molecular tag, which can later selectively react with a radiolabeled agent via a rapid bioorthogonal reaction. Similarly, pretargeting can be applied for spatiotemporally controlled drug delivery. ${ }^{2,17-21}$ In this approach, a highly potent drug is bioorthogonally cleaved from a pretargeted mAbconjugate upon its accumulation at the site of disease, achieving higher local drug concentrations while simultaneously reducing systemic toxicity to healthy tissue. Due to its 
fast reaction kinetics, high selectivity and biocompatibility, the inverse electron demand Diels-Alder (IEDDA)-initiated ligation between a 1,2,4,5-tetrazine (Tz) and a transcyclooctene (TCO) has become state-of-the-art for time-critical application of in vivo chemistry, as well as bioorthogonally controlled drug delivery by using Tz-triggered elimination of cleavable TCOs ('click-to-release'). ${ }^{2,13,19-24}$ Currently, the understanding of the scope and limitations of IEDDA-initiated ligation for pretargeting strategies in vivo is limited and the design of suitable Tz-derivatives for this purpose is mainly a 'trial-and-error' game, heavily depending on the time-intensive development of radiolabeled compounds for in vivo evaluation. Current labeling strategies have, so far, mostly been focused on chelator approaches, overall impeding the use of compound libraries for systematic studies. ${ }^{14,25,26}$ In order to enable the rational design of tetrazine derivatives for in vivo chemistry, it is important to understand the structure-property relationship between the physicochemical parameters of Tz-derivatives and their capability to reach and react in vivo with TCOmodified (bio)molecules accumulated at the target site of interest.

The aim of the present study was to identify and explore the key parameters that influence the in vivo performance of Tz-derivatives (Figure 1). Consequently, we prepared a library of Tzderivatives with a set of different rate constants (in the reaction with TCO), lipophilicities, and topological polar surface areas (TPSA), and applied a pretargeted blocking assay to evaluate their ligation performance in vivo. The blocking effect of each $\mathrm{Tz}$ was correlated with its lipophilicity (calculated $\log D_{7.4}\left(\log D_{7.4}\right)$ values), calculated TPSA as well as with its IEDDA reactivity. The obtained results were verified by in vivo pretargeted PET imaging of a set of selected Tz-derivatives radiolabeled with fluorine-18. 


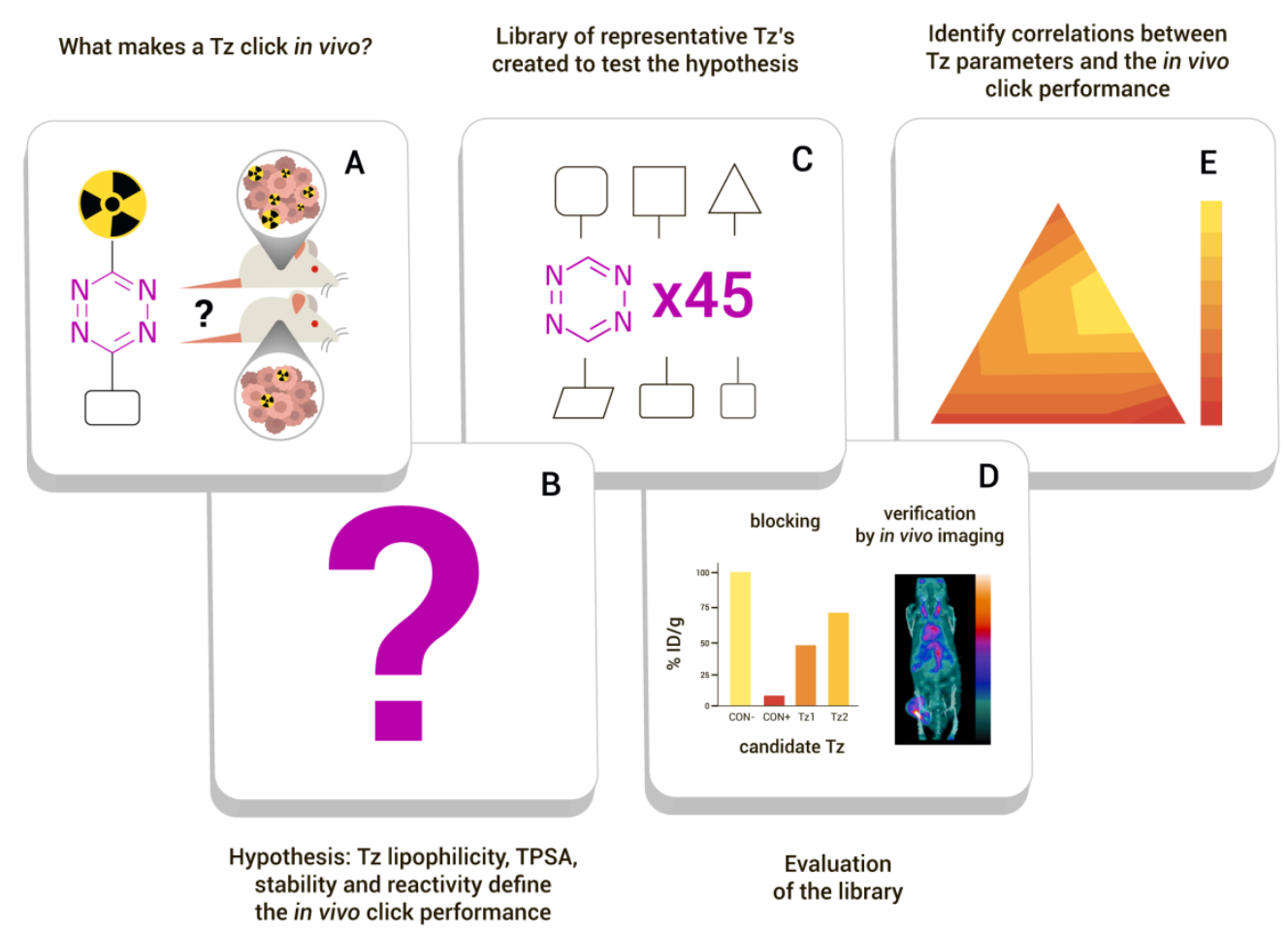

Figure 1. General strategy and workflow of this study. (A) The research question: Which key parameters determine the efficiency of the in vivo performance of tetrazines? (B) We hypothesized that lipophilicity, TPSA, stability and/or reactivity of the Tz determine its in vivo ligation efficiency. (C) To test this hypothesis, a compound library was created and (D) evaluated with emphasis on the capability for in vivo click reaction. (E) Finally, these results were analyzed to identify and confirm the correlation between key parameters and in vivo ligation performance.

\section{RESULTS AND DISCUSSION}

\section{Experimental design and preparation of the Tz-library}

A structurally diverse library of $45 \mathrm{Tz}$-derivatives was prepared, covering a wide spectrum of physicochemical properties, in particular calculated TPSAs between 60-350 $\AA^{2}$ and different lipophilicities, with calculated $\log D_{7.4}$ values $\left(\log D_{7.4}\right)$ ranging from approximately -7.0 to 2.5 (Table 1; for synthetic procedures and details see Supporting Information). The Tzscaffolds (A-L) include mono- and disubstituted methyl-, phenyl-, 2-pyrimidyl-, and 2pyridyl-substituted Tz-derivatives with second-order rate constants for the reaction with TCO ranging from 1.4 to $230 \mathrm{M}^{-1} \mathrm{~s}^{-1}$ in 1,4-dioxane at $25{ }^{\circ} \mathrm{C}$, and from 1,100 to $73,000 \mathrm{M}^{-1} \mathrm{~s}^{-1}$ in buffered aqueous solution at $37^{\circ} \mathrm{C}$. Table 1 provides an overview of the synthesized Tzlibrary and displays the measured rate constants and calculated physicochemical properties of each Tz. Several compounds were obtained as copper(II) complexes (for details see the Supporting Information), which was taken into account in the calculation of $\operatorname{cog} D_{7.4}$ and TPSA (as described in the Notes of Table 1). 
Table 1. Structural scaffolds, calculated physicochemical properties (TPSA and $\operatorname{cog} D_{7.4}$ ), measured second-order rate constants for the ligation with TCO, and blocking efficiencies of all investigated Tz-derivatives.
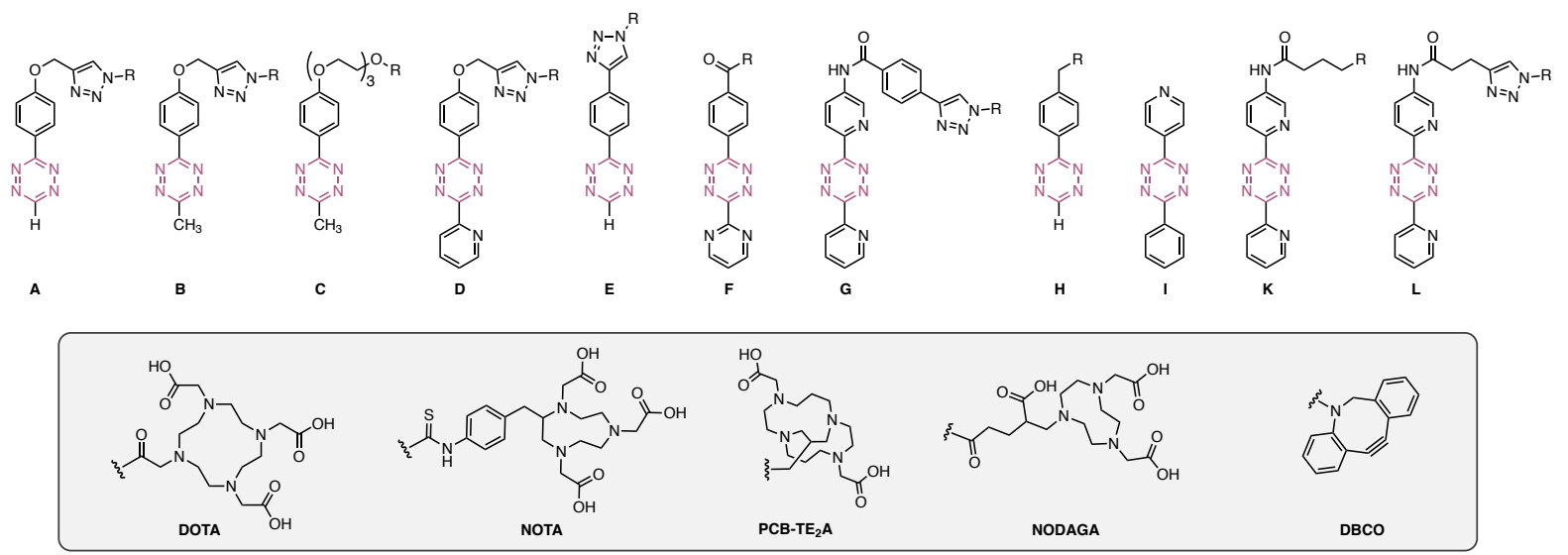

\begin{tabular}{|c|c|c|c|c|c|c|c|c|}
\hline $\mathbf{T z}$ & Tz-scaffold & $\mathbf{R}$ & $\operatorname{cog} D_{7.4^{a}}$ & $\begin{array}{c}\text { TPSA }^{\mathbf{a}} \\
\left(\AA^{2}\right)\end{array}$ & $\begin{array}{l}\text { Rate constant } \\
(1,4 \text {-dioxane, } \\
\left.25^{\circ} \mathrm{C}_{,} \mathrm{M}^{-1} \mathrm{~s}^{-1}\right)^{\mathrm{b}}\end{array}$ & $\begin{array}{l}\text { Rate constant } \\
\quad(\mathrm{DPBS}, \\
\left.37^{\circ} \mathrm{C}, \mathrm{M}^{-1} \mathrm{~s}^{-1}\right)^{\mathrm{b}}\end{array}$ & $\begin{array}{l}\text { Blocking } \\
\text { effect } \\
(\%)^{\mathrm{c}}\end{array}$ & $\begin{array}{c}\text { \% Tumor Uptake } \\
\text { of }\left[\begin{array}{c}111 \\
\text { In }] 46 \text { after } \\
\text { blocking }\end{array}\right.\end{array}$ \\
\hline
\end{tabular}

\begin{tabular}{|c|c|c|c|c|c|c|c|c|}
\hline 1 & A & $\overbrace{}^{F}$ & 0.29 & 91 & 72 & 39,000 & 9 & 91 \\
\hline 2 & A & & -0.06 & 119 & 72 & 39,000 & 4 & 96 \\
\hline 3 & A & & -1.53 & 161 & 72 & 39,000 & 80 & 20 \\
\hline 4 & A & & -2.86 & 217 & 72 & 39,000 & 95 & 5 \\
\hline 5 & B & & 0.89 & 91 & 1.4 & 1,100 & 9 & 91 \\
\hline 6 & B & & 0.54 & 119 & 1.4 & 1,100 & 1 & 99 \\
\hline 7 & $\mathrm{~B}$ & & -0.93 & 161 & 1.4 & 1,100 & 13 & 87 \\
\hline 8 & B & & -5.81 & 221 & 1.4 & 1,100 & 49 & 51 \\
\hline 9 & $\mathrm{C}$ & & -2.19 & 114 & 1.4 & 1,100 & 14 & 86 \\
\hline 10 & $\mathrm{C}$ & & -2.05 & 214 & 1.4 & 1,100 & 32 & 68 \\
\hline 11 & $\mathrm{C}$ & & -3.2 & 184 & 1.4 & 1,100 & 34 & 66 \\
\hline 12 & $\mathrm{D}$ & & 1.89 & 104 & 13 & n.d. & 0 & 100 \\
\hline 13 & $\mathrm{D}$ & & 1.53 & 132 & 13 & n.d. & 0 & 100 \\
\hline 14 & $\mathrm{D}$ & & 0.06 & 174 & 13 & n.d. & 24 & 76 \\
\hline 15 & $\mathrm{D}$ & & -1.98 & 111 & 13 & n.d. & 78 & 22 \\
\hline 16 & $\mathrm{D}$ & & -6.65 & 167 & 13 & n.d. & 79 & 21 \\
\hline 17 & $\mathrm{E}$ & & 0.65 & 82 & 200 & 60,000 & 0 & 100 \\
\hline 18 & $\mathrm{E}$ & & 0.29 & 109 & 200 & 60,000 & 28 & 72 \\
\hline 19 & $\mathrm{E}$ & & -1.18 & 152 & 200 & 60,000 & 76 & 24 \\
\hline 20 & $\mathrm{E}$ & & -2.46 & 208 & 200 & 60,000 & 94 & 6 \\
\hline 21 & $\mathrm{~F}$ & $-\mathrm{OH}$ & -1.97 & 114 & 83 & n.d. & 87 & 13 \\
\hline 22 & $\mathrm{~F}$ & & 0.64 & 134 & 83 & n.d. & 27 & 73 \\
\hline 23 & $\mathrm{~F}$ & & 0.12 & 126 & 83 & n.d. & 72 & 28 \\
\hline 24 & $\mathrm{~F}$ & & -4.2 & 278 & 83 & n.d. & 96 & 4 \\
\hline 25 & G & & 2.46 & 137 & 230 & 73,000 & 16 & 84 \\
\hline 26 & G & & 2.10 & 164 & 230 & 73,000 & 30 & 70 \\
\hline 27 & $\mathrm{G}$ & & 0.63 & 207 & 230 & 73,000 & 51 & 49 \\
\hline 28 & $\mathrm{H}$ & & 1.11 & 90 & 210 & 58,000 & 45 & 55 \\
\hline 29 & $\mathrm{H}$ & $\mathrm{H}$ & -0.14 & 78 & 210 & 58,000 & 55 & 45 \\
\hline 30 & $\mathrm{H}$ & 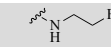 & -0.18 & 63 & 210 & 58,000 & 62 & 38 \\
\hline
\end{tabular}




\begin{tabular}{|c|c|c|c|c|c|c|c|c|}
\hline 31 & $\mathrm{H}$ & ${ }_{\mathrm{H}}^{\mathrm{N}}{ }_{\mathrm{CH}_{3}}$ & -0.41 & 80 & 210 & 58,000 & 60 & 40 \\
\hline 32 & $\mathrm{H}$ & & -3.03 & 100 & 210 & 58,000 & 86 & 14 \\
\hline 33 & $\mathrm{H}$ & $-\mathrm{N}\left(\mathrm{CH}_{2} \mathrm{COOH}\right)_{2}$ & -6.89 & 129 & 210 & 58,000 & 97 & 3 \\
\hline 34 & $\mathrm{H}$ & & -4.4 & 202 & 210 & 58,000 & 95 & 5 \\
\hline 35 & $\mathrm{H}$ & & -5.16 & 320 & 210 & 58,000 & 96 & 4 \\
\hline 36 & I & 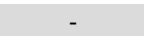 & 1.79 & 61 & 10 & n.d. & 0 & 100 \\
\hline 37 & $\mathrm{~K}$ & & -0.77 & 129 & 230 & 73,000 & 76 & 24 \\
\hline 38 & $\mathrm{~K}$ & & -2.23 & 161 & 230 & 73,000 & 83 & 17 \\
\hline 39 & $\mathrm{~K}$ & & -2.37 & 143 & 230 & 73,000 & 96 & 4 \\
\hline 40 & $\mathrm{~K}$ & & -3.81 & 263 & 230 & 73,000 & 97 & 3 \\
\hline 41 & $\mathrm{~K}$ & & -4.13 & 362 & 230 & 73,000 & 99 & 1 \\
\hline 42 & $\mathrm{~K}$ & & 1.62 & 129 & 230 & 73,000 & 75 & 25 \\
\hline 43 & $\mathrm{~L}$ & $\varkappa^{\mathrm{F}}$ & 0.84 & 137 & 230 & 73,000 & 67 & 33 \\
\hline 44 & $\mathrm{~L}$ & 3 & 0.48 & 164 & 230 & 73,000 & 72 & 28 \\
\hline 45 & $\mathrm{~L}$ & $\mathrm{HO}_{\mathrm{H}}$ & -0.99 & 207 & 230 & 73,000 & 99 & 1 \\
\hline
\end{tabular}

Notes: ${ }^{a}$ The distribution coefficient at physiological $\mathrm{pH}\left(\log D_{7.4}\right)$ and TPSA were calculated using the software Chemicalize. Tetrazines conjugated to DOTA were calculated with chelated trivalent cations, Tzs with other chelators with bivalent cations. becond-order rate constants for the Tz scaffolds A-L were determined by stopped-flow spectrophotometry ( $\mathrm{n} \geq 4$ ), monitoring the reaction of representative tetrazines with unsubstituted trans-cyclooctene (TCO) at $25^{\circ} \mathrm{C}$ in 1,4-dioxane, and with TCO-PEG 4 (modified TCO-5ax-OH, 'minor-TCO') in Dulbecco's phosphate buffered saline (DBPS) at $37{ }^{\circ} \mathrm{C}$. ' $\mathrm{n} \geq 3$; (see Supporting Information, Table S1 and Table S2).

\section{Pretargeted blocking studies}

The blocking assay allows for the assessment of the in vivo ligation performance of unlabeled Tz-derivatives, avoiding the need for time-consuming development of radiolabeling procedures, as well as the preparation of labeled analogs or surrogates. The assay was inspired by receptor blocking experiments and based on the pretargeted imaging approach reported by Rossin et al.. ${ }^{13,27}$ An ${ }^{111}$ In-labeled Tz ([111 In]46, see Supporting Information, Fig. S1) was used in pair with TCO-modified CC49, a non-internalizing mAb that targets the tumor-associated glycoprotein 72 (TAG72), ${ }^{13,27}$ as a benchmark model for the in vivo ligation. To study the in vivo ligation performance of Tz-derivatives 1-45, BALB/c mice bearing LS174T colon carcinoma xenografts were injected intravenously (i.v.) with CC49TCO $72 \mathrm{~h}$ prior to i.v. injection of the unlabeled Tz, followed by administration of [ $\left.{ }^{111} \mathrm{In}\right] 461$ $\mathrm{h}$ later (for experimental details see Supporting Information). The animals were euthanized after $22 \mathrm{~h}$ and an ex vivo biodistribution was carried out to quantify the tumor uptake of $\left[{ }^{111} \mathrm{In}\right] 46$ (Figure 2A). The efficiency of the in vivo ligation of the unlabeled Tz can thus be correlated to a reduced uptake of $\left[{ }^{111} \mathrm{In}\right] \mathbf{4 6}$ (Fig. 2A). As a control, blocking was performed using the non-radioactive precursor of $\left[{ }^{111} \mathrm{In}\right] 46$ (DOTA-Tz 41, see Supporting Information), which blocked $\geq 99 \%$ of the $\left[{ }^{111} \mathrm{In}\right] \mathbf{4 6}$ tumor uptake. A group of CC49-TCO pretreated mice were injected exclusively with $\left[{ }^{111} \mathrm{In}\right] \mathbf{4 6}$ (without blocking) and the determined uptake was 
used as reference value $(100 \%)$ to normalize the observed changes in tumor uptake in blocking experiments.

Figure 2A displays the blocking assay and 2B summarizes the results for the entire Tz-library in the assay. The highest blocking efficiencies (95-99\%) were observed for the Tz-chelator conjugates 4, 24, 35 and 41, the Tz-carboxylic acids 33 and 39, the Tz-PEG derivative 40, and the Tz-sugar conjugate 45. All of these probes include H-phenyl-, pyrimidyl-phenyl-, or bis(pyridyl)-Tz-scaffolds with second-order rate constants for the reaction with TCO $(1,4-$ dioxane, $25{ }^{\circ} \mathrm{C}$ ) of $>70 \mathrm{M}^{-1} \mathrm{~s}^{-1}$ (cf. Table 1). Further details of the blocking studies are provided in the Supporting Information (Figure S2). Next, potential correlations between the blocking effect, the $\operatorname{cog} D_{7.4}$ and the TPSA, as well as IEDDA reactivity were investigated. As expected, high IEDDA reactivity was shown to directly correlate with the blocking effect and thus confirmed to be a key parameter for the in vivo ligation performance of $\mathrm{Tz}$ derivatives (Fig. 2C, 2D). We did not observe a strong correlation between the blocking effect and TPSA (Figure S14). However, a distinct relationship between $\operatorname{cog} D_{7.4}$ values and the blocking effect was evidently observed when comparing Tz-derivatives with similar IEDDA reactivity (Fig. 2C, 2D and S15). For all Tz-scaffolds a Pearson's correlation coefficient $>0.78$ was found. Our results show that high IEDDA reactivity $\left(>50,000 \mathrm{M}^{-1} \mathrm{~s}^{-1}\right)$ and a $\operatorname{cog} D_{7.4}$ of -3 or lower are strong indicators for high in vivo ligation performance of Tzderivatives in pretargeting approaches using the described tumor model (Figure 2). 
A

B
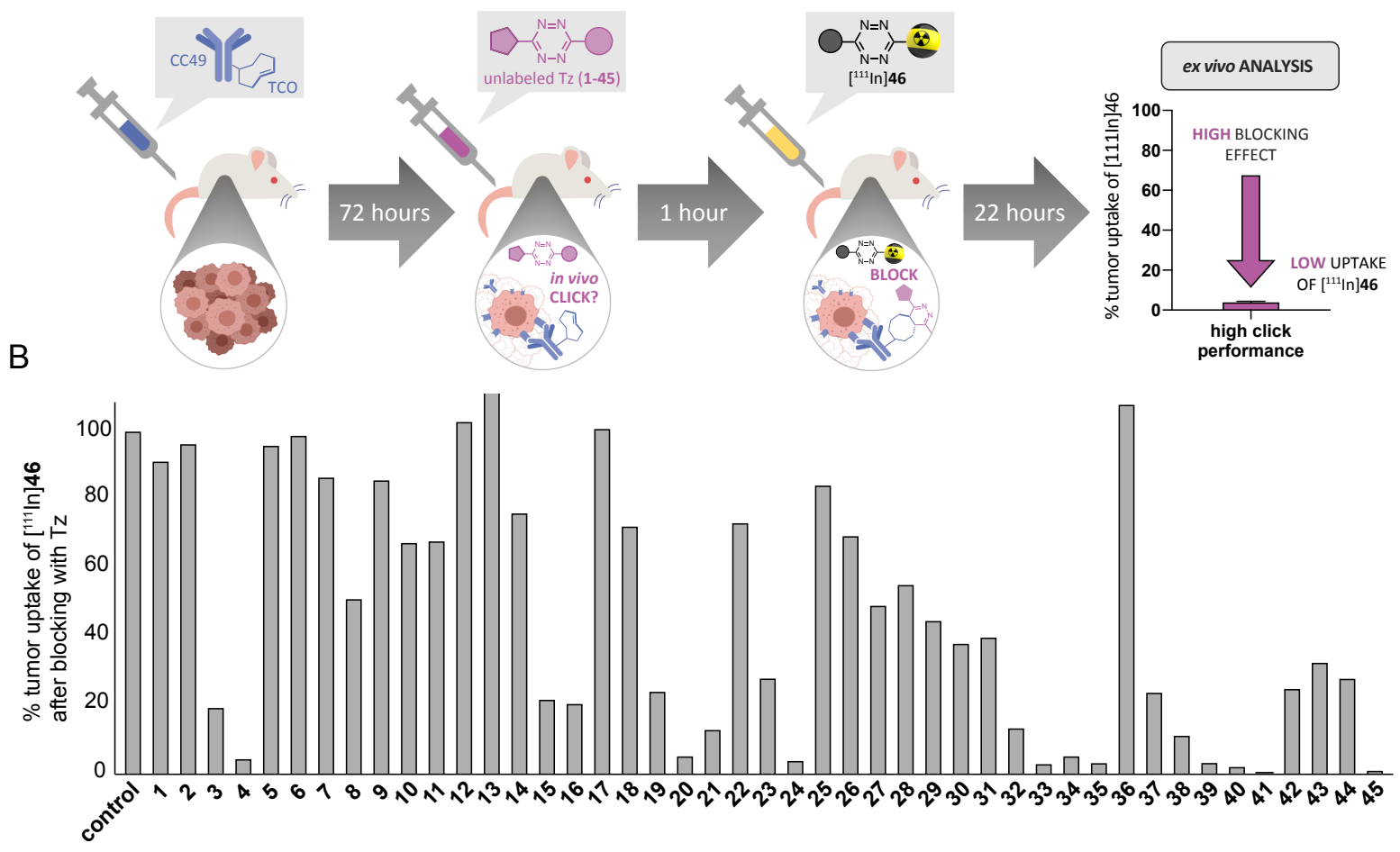

C

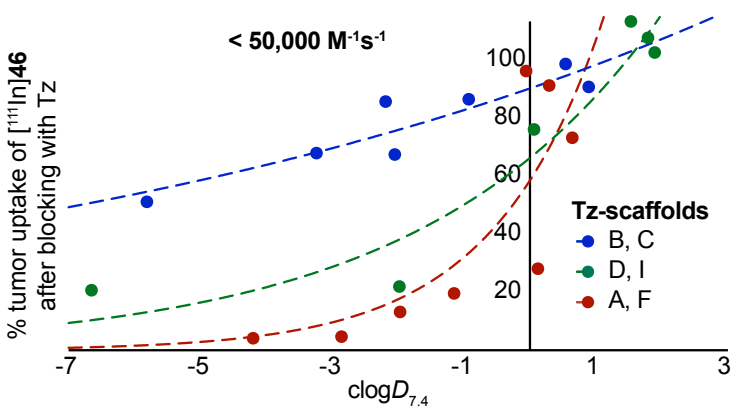

D

E

\begin{tabular}{|c|c|c|c|c|c|}
\hline \multicolumn{6}{|c|}{ Tz-scaffolds grouped by IEDDA reactivity (second-order rate constants, $\mathrm{M}^{-1} \mathrm{~s}^{-1}$ ) } \\
\hline Tz-scaffolds (see Table 1) & - B,C & $\bullet \mathrm{D}, \mathrm{I}$ & - A,F & - E,H & - $\mathrm{G}, \mathrm{L}, \mathrm{K}$ \\
\hline 1,4-dioxane, $25^{\circ} \mathrm{C} a$ & 1.4 & $10-13$ & $72-83$ & $200-210$ & 230 \\
\hline DPBS buffer, $37^{\circ} \mathrm{C}^{b}$ & 950 & n.d. & $39,000^{c}$ & $58,000-60,000$ & 73,000 \\
\hline Pearson's correlation coefficient $(r)$ & 0.92 & 0.89 & 0.78 & 0.94 & 0.86 \\
\hline$p$-value & 0.003 & 0.017 & 0.021 & $<0.0001$ & $<0.001$ \\
\hline$n$ & 7 & 6 & 8 & 12 & 12 \\
\hline
\end{tabular}

Figure 2. Results from the blocking assay. (A) Schematic display of the blocking assay. (B) The blocking effect of non-radiolabeled Tz was determined as the change in tumor uptake of $\left[{ }^{111} \mathrm{In}\right] 4622 \mathrm{~h}$ p.i. Each Tz was administered $1 \mathrm{~h}$ prior to $\left[{ }^{111} \mathrm{In}\right] 46$ and the uptake normalized to a group of animals were no blocking was performed (control). Data represent mean from $n=3$ mice/group, detailed information can be found in the SI. (C and D) Correlation of blocking effect and $\operatorname{cog} D_{7.4}$ for Tz-derivatives with similar IEDDA reactivity. Data was fitted to exponential growth equation $\mathrm{Y}=\mathrm{Y}_{0} \mathrm{e}^{\mathrm{kx}}$ (dotted line). (E) Statistical analysis of the correlation between tumor uptake and $\operatorname{clog} D_{7.4}$ for the different groups of Tz-derivatives. Pearson's correlation coefficient $(r)$ describes the goodness of fit between the blocking effect and $\operatorname{cog} D_{7.4}$. Notes: ${ }^{a}$ Reaction of representative Tz with unsubstituted TCO $;{ }^{b}$ Reaction of representative Tz with TCO-PEG $4 ;{ }^{c}$ Measured for Tz-scaffold A only; $n . d$. = not determined.

\section{Experimental design of a $\left[{ }^{18} \mathbf{F}\right] \mathrm{Tz}$ library}

In order to verify that the results from the blocking study can be used to predict the outcome for in vivo PET imaging, $18 \mathrm{Tz}$-derivatives from the first library were selected. The selection was based on criteria such as, the possibility for ${ }^{18} \mathrm{~F}$-labeling, structural diversity, 
lipophilicities and distinct IEDDA reactivities. For this purpose, we decided to use an indirect radiolabeling approach, enabling the combination of different building blocks to rapidly access a series of ${ }^{18} \mathrm{~F}$-labeled Tz-derivatives. The Cu-catalyzed azide-alkyne [3+2] cycloaddition (CuAAC) appeared to be suitable in this respect, as it allows for fast and efficient radiolabeling under mild reaction conditions. ${ }^{28-32}$ Six precursor Tz-alkynes (I-VI) were prepared and reacted with three ${ }^{18} \mathrm{~F}$-labeled azides $\left(\left[{ }^{18} \mathrm{~F}\right] \mathbf{A z 1}-\mathbf{A z 3}\right)$ to obtain 18 different $\left[{ }^{18} \mathrm{~F}\right]$ Tz-probes (Table 2).

\section{Indirect ${ }^{18}$ F-labeling of a $\mathrm{Tz}$ series via $\mathrm{Cu}$-catalyzed click chemistry}

Azide building blocks were ${ }^{18} \mathrm{~F}$-labeled using fully automated procedures to afford $\left[{ }^{18} \mathrm{~F}\right] \mathbf{A z} 1-$ $\left[{ }^{18} \mathrm{~F}\right] \mathbf{A z 3}$ (Scheme $\left.\mathrm{S} 15\right)^{33,34}$ and Tz-alkynes I-VI were synthesized as described in the Supporting Information. Subsequent radiolabeling via the $\mathrm{CuAAC}$ was achieved in various yields, up to approximately 70\% (Table 2). Applied conditions for the CuAAC differed depending on the substituents attached to the Tz-scaffold. In general, radiolabeling was carried out at room temperature with reaction times of 10-15 min using aqueous solutions of $\mathrm{CuSO}_{4}$, sodium ascorbate and disodium bathophenanthroline disulfonate (BPDS). For the synthesis of the bis(pyridyl)Tz-derivatives $\left[{ }^{18} \mathrm{~F}\right] \mathbf{2 5},\left[{ }^{18} \mathrm{~F}\right] 44$ and $\left[{ }^{18} \mathrm{~F}\right] \mathbf{4 5}$, increased amounts of the catalysts, longer reaction times (20-25 $\mathrm{min})$ and elevated temperatures $\left(120^{\circ} \mathrm{C}\right)$ were required in order to reach radiochemical conversions (RCCs) of $\geq 70 \%$. A possible reason for the harsher conditions required for this scaffold may be a result from coordination of $\mathrm{Cu}$ by the bis(pyridyl)-Tz moiety. Radiochemical yields (RCYs) and molar activities $\left(\mathrm{A}_{m}\right)$ for all ${ }^{18} \mathrm{~F}$-labeled Tz-derivatives are presented in Table 2. Radiochemical purities (RCPs) of the isolated compounds were high $(>90 \%)$, except for $\left[{ }^{18} \mathrm{~F}\right] 25$ and $\left[{ }^{18} \mathrm{~F}\right] 26(83-85 \%)$ due to radiolysis (observed for $\left[{ }^{18} \mathrm{~F}\right] 25$ ), undesired decomposition, and difficult separation of the resulting byproducts. During the radiolabeling partial reduction of $\left[{ }^{18} \mathrm{~F}\right] 19$ and $\left[{ }^{18} \mathrm{~F}\right] 44$ to the corresponding dihydro-Tz (cf. Fig. S73 and S74) was observed. However, these Tzderivatives were reoxidized using phenyliodonium diacetate (PIDA). In the case of $\left[{ }^{18} \mathrm{~F}\right] 44$, complete reduction to the dihydro-Tz (using ascorbic acid) and reoxidation upon purification could be applied to prevent radiolysis. Excess PIDA and byproducts were removed during solid-phase extraction to obtain $\left[{ }^{18} \mathrm{~F}\right] 44$ in a RCP of $98 \%$ (Table 2; for details see the Supporting Information). Moreover, during the synthesis of $\left[{ }^{18} \mathrm{~F}\right] 45$ an alternative deprotection method for the azide $\left(\left[{ }^{18} \mathrm{~F}\right] \mathbf{A z 3}\right)$ was required to avoid decomposition of the Tzscaffold during the CuAAC. All ${ }^{18} \mathrm{~F}$-labeled Tz-derivatives were formulated in $0.9 \%$ saline 
prior further studies. Overall, radiofluorination via the CuAAC allowed for the preparation of a structurally diverse series of ${ }^{18} \mathrm{~F}$-labeled Tz-derivatives. In contrast to routinely used direct radiofluorination methods, this building block approach gave access to highly reactive $\left[{ }^{18} \mathrm{~F}\right] \mathrm{Tz}$-probes, using Tz-scaffolds that have previously been reported to be inaccessible. ${ }^{1,35,36}$

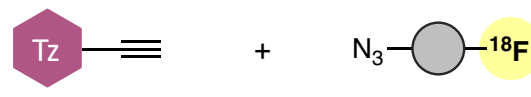

Tz-alkyne
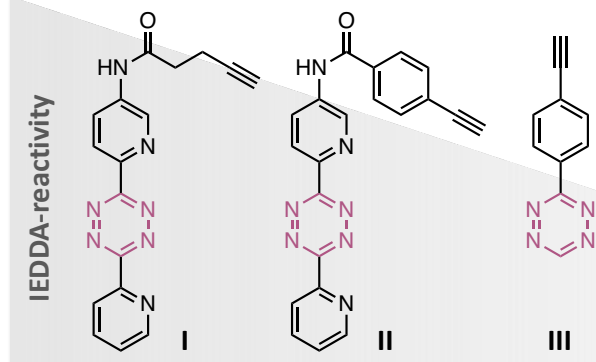

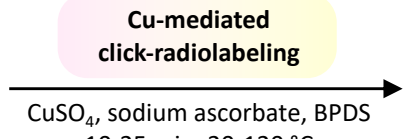

$10-25 \min , 20-120^{\circ} \mathrm{C}$

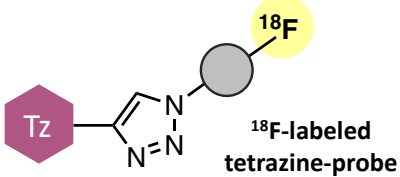

Table 2. Cu-mediated click-radiolabeling for the synthesis of ${ }^{18} \mathrm{~F}$-labeled Tz-probes.

\begin{tabular}{|c|c|c|c|c|c|c|c|}
\hline Tetrazine & $\begin{array}{c}\text { Tz-alkyne } \\
(\text { I-VI) }\end{array}$ & $\begin{array}{c}\text { Azide-functionalized } \\
{ }^{18} \text { F-click-agent }\end{array}$ & $\operatorname{RCY}(\%)^{a}$ & $\begin{array}{c}\mathbf{A}_{\boldsymbol{m}}^{b} \\
(\mathrm{GBq} / \mu \mathrm{mol})\end{array}$ & $\mathbf{R C P}(\%)^{c}$ & $\begin{array}{l}\text { In vivo stability } \\
\left(\% \text { intact }\left[{ }^{18} \mathrm{~F}\right] \mathrm{Tz}\right. \\
\text { after } 30 \mathrm{~min})\end{array}$ & $\begin{array}{c}\text { Blocking effect } \\
(\%)\end{array}$ \\
\hline$\left[{ }^{18} \mathrm{~F}\right] 1$ & IV & {$\left[{ }^{18} \mathrm{~F}\right] \mathbf{A z} 1$} & $25^{c}$ & 55 & 99 & 90 & 9 \\
\hline$\left[{ }^{18} \mathrm{~F}\right] 2$ & IV & {$\left[{ }^{18} \mathrm{~F}\right] \mathbf{A z 2}$} & 23 & 22 & 96 & 37 & 4 \\
\hline$\left[{ }^{18} \mathrm{~F}\right] 3$ & IV & {$\left[{ }^{18} \mathrm{~F}\right] \mathbf{A z z}$} & 61 & 31 & 98 & 76 & 81 \\
\hline$\left[{ }^{18} \mathrm{~F}\right] 5$ & VI & {$\left[{ }^{18} \mathrm{~F}\right] \mathbf{A z} \mathbf{1}$} & $14^{*}$ & 106 & $\geq 99$ & 26 & 10 \\
\hline$\left[{ }^{18} \mathrm{~F}\right] 6$ & VI & {$\left[{ }^{18} \mathrm{~F}\right] \mathbf{A z 2}$} & 33 & 100 & $\geq 99$ & 85 & 1 \\
\hline$\left[{ }^{18} \mathbf{F}\right] 7$ & VI & {$\left[{ }^{18} \mathrm{~F}\right] \mathbf{A z 3}$} & 52 & 230 & $\geq 99$ & 60 & 3 \\
\hline$\left[{ }^{18} \mathrm{~F}\right] 12$ & V & {$\left[{ }^{18} \mathrm{~F}\right] \mathbf{A z} \mathbf{1}$} & $1^{*}$ & 107 & 96 & 10 & 0 \\
\hline$\left[{ }^{18} \mathrm{~F}\right] 13$ & $\mathbf{V}$ & {$\left[{ }^{18} \mathrm{~F}\right] \mathbf{A z 2}$} & 11 & 21 & 94 & 16 & 0 \\
\hline$\left[{ }^{18} \mathrm{~F}\right] 14$ & $\mathbf{V}$ & {$\left[{ }^{18} \mathrm{~F}\right] \mathbf{A z z}$} & 68 & 102 & 98 & 43 & 24 \\
\hline$\left[{ }^{18} \mathrm{~F}\right] 17$ & III & {$\left[{ }^{18} \mathrm{~F}\right] \mathbf{A z} \mathbf{z}$} & $8^{*}$ & 209 & 98 & 32 & 0 \\
\hline$\left[{ }^{18} \mathrm{~F}\right] 18$ & III & {$\left[{ }^{18} \mathrm{~F}\right] \mathbf{A z z}$} & 17 & 37 & 92 & 22 & 29 \\
\hline$\left[{ }^{18} \mathrm{~F}\right] 19$ & III & {$\left[{ }^{18} \mathrm{~F}\right] \mathbf{A z 3}$} & 59 & 29 & 98 & 87 & 76 \\
\hline$\left[{ }^{18} \mathrm{~F}\right] 25$ & II & {$\left[{ }^{18} \mathrm{~F}\right] \mathbf{A z} 1$} & $16^{*}$ & n.d. & 83 & n.d. & 16 \\
\hline$\left[{ }^{18} \mathrm{~F}\right] 26$ & II & {$\left[{ }^{18} \mathrm{~F}\right] \mathbf{A z z} 2$} & 36 & 54 & $\geq 85$ & 27 & 30 \\
\hline$\left[{ }^{18} \mathbf{F}\right] 27$ & II & {$\left[{ }^{18} \mathrm{~F}\right] \mathbf{A z 3}$} & $18^{*}$ & n.d. & $\geq 90$ & n.d. & 51 \\
\hline$\left[{ }^{18} \mathrm{~F}\right] 43$ & I & {$\left[{ }^{18} \mathrm{~F}\right] \mathbf{A z} \mathbf{1}$} & 1 & 5 & 90 & 10 & 67 \\
\hline$\left[{ }^{18} \mathrm{~F}\right] 44$ & I & {$\left[{ }^{18} \mathrm{~F}\right] \mathbf{A z 2}$} & 20 & 85 & 98 & n.d. & 72 \\
\hline$\left[{ }^{18} \mathrm{~F}\right] 45$ & I & {$\left[{ }^{18} \mathrm{~F}\right] \mathbf{A z 3}$} & 11 & 151 & $\geq 90$ & 42 & 99 \\
\hline
\end{tabular}

Notes: Details on experimental procedures are provided in the Supporting Information. ${ }^{a}$ RCYs were decay-corrected to the starting amount of radioactivity for the respective azide or ${ }^{*} \mathrm{RCY}$ was determined starting from ${ }^{18} \mathrm{~F}^{-}$. ${ }^{b}$ Molar activities $\left(\mathrm{A}_{m}\right)$ differ due to the use of different cyclotrons (see Supporting Information). ${ }^{c} \mathrm{RCP}$ was determined by radio-HPLC. ${ }^{d}$ In vivo stability of $\left[{ }^{18} \mathrm{~F}\right] \mathrm{Tz}$ was assessed by determining the fraction $(\%)$ of radioactivity corresponding to intact compound after $30 \mathrm{~min}(n=4)$ from radio-TLC analysis. n.d. = not determined.

\section{In vivo stability of ${ }^{18} \mathbf{F}$-labeled Tz-derivatives in naïve mice}

Next, we investigated whether there is a relationship between the in vivo stability of Tzderivatives and their blocking ability. Fifteen ${ }^{18} \mathrm{~F}$-labeled tetrazines were studied in naïve 
mice and collected plasma samples were analyzed by radio-TLC (for details see Supporting Information) for stability assessment (Table 2, Figure S75 and S76). Interestingly, the in vivo stability had only a limited or even no effect on the in vivo ligation performance as evaluated in the blocking study (cf. Table 1). Consequently, six $\left[{ }^{18} \mathrm{~F}\right] \mathrm{Tz}\left(\left[{ }^{18} \mathrm{~F}\right] \mathbf{1},\left[{ }^{18} \mathrm{~F}\right] \mathbf{3},\left[{ }^{18} \mathrm{~F}\right] \mathbf{1 9},\left[{ }^{18} \mathrm{~F}\right] \mathbf{2 6}\right.$, $\left[{ }^{18} \mathrm{~F}\right] 44$, and $\left.\left[{ }^{18} \mathrm{~F}\right] \mathbf{4 5}\right)$ were selected for further in vivo studies solely based on the IEDDAreactivity (second-order rate constants between 72 and $\left.230 \mathrm{M}^{-1} \mathrm{~s}^{-1}\right)$ and lipophilicity $\left(\operatorname{cog} D_{7.4}\right.$ between -1.53 and 2.10). These radiolabeled Tz-probes were used to investigate if the results from the blocking assay can be translated to pretargeted PET imaging at tracer doses.

\section{Pretargeted PET imaging}

Of the six Tz-probes selected for evaluation in pretargeted PET imaging studies, four compounds (3, 19, 44 and 45) showed a good to excellent blocking effect (72-99\%), while two probes (1 and 26) only showed limited effect ( $9 \%$ for $\mathbf{1}$ and $30 \%$ for $\mathbf{2 6}$ ). The latter were included to verify that blocking results can reliably be used to predict the capability of radiolabeled $\mathrm{Tz}$ for pretargeted in vivo chemistry.

Mice ( $n=3-4$ per group) were injected i.v. with either CC49-TCO or $0.9 \%$ saline (control experiments). After $72 \mathrm{~h},{ }^{18} \mathrm{~F}$-labeled $\mathrm{Tz}(5-10 \mathrm{MBq})$ were administered and the mice were PET/CT-scanned $1 \mathrm{~h}$ p.i. A $3 \mathrm{D}$ region of interest (ROI) was created on the entire tumor volume, as well as heart and muscle tissue, and the uptake was quantified as percentage of the injected dose per gram (mean \% ID/g), tumor-to-blood (T/B) and tumor-to-muscle (T/M) ratios (Fig. 3A-D, Table S3 and S4).

The tumor uptake of the different ${ }^{18} \mathrm{~F}$-labeled Tz-probes was at a rather similar level, however, $\left[{ }^{18} \mathrm{~F}\right] \mathbf{3},\left[{ }^{18} \mathrm{~F}\right] \mathbf{1 9}$ and $\left[{ }^{18} \mathrm{~F}\right] \mathbf{4 5}$ showed a significantly increased tumor accumulation in mice pretreated with CC49-TCO compared to control animals (Figure 3A and 3F, Table S3 and S4). As expected and in accordance with blocking results, we did not observe significant tumor uptake of $\left[{ }^{18} \mathrm{~F}\right] \mathbf{1}$ and $\left[{ }^{18} \mathrm{~F}\right] \mathbf{2 6}$. In the case of $\left[{ }^{18} \mathrm{~F}\right] \mathbf{4 4}$, no increase in tumor accumulation was observed in mice pretreated with TCO-modified mAb. However, this Tz showed higher radioactivity levels in the heart in mice pretreated with CC49-TCO compared to controls (2.5 $\pm 0.7 \% \mathrm{ID} / \mathrm{g}$ and $1.5 \pm 0.2 \% \mathrm{ID} / \mathrm{g}$, respectively; Figure 3B, Table S1). This indicates that $\left[{ }^{18} \mathrm{~F}\right] 44$ binds to $\mathrm{mAb}$ still circulating in the blood pool. This difference was also observed for the three ${ }^{18} \mathrm{~F}$-labeled Tz-derivatives showing specific tumor accumulation $\left(\left[{ }^{18} \mathrm{~F}\right] \mathbf{3},\left[{ }^{18} \mathrm{~F}\right] 19\right.$ and $\left[{ }^{18} \mathrm{~F}\right] \mathbf{4 5}$ ), but not for the non-accumulating probes $\left[{ }^{18} \mathrm{~F}\right] \mathbf{1}$ and $\left[{ }^{18} \mathrm{~F}\right] \mathbf{2 6}$ (Figure $3 \mathrm{~B}$ ). Binding to residual $\mathrm{mAb}$ in the blood pool is a frequently reported challenge in pretargeted imaging approaches, and has been addressed by the development of clearing agents. ${ }^{14,37-39}$ However, 
ligation in blood did not hinder the investigation of the in vivo ligation performance of ${ }^{18} \mathrm{~F}$ labeled Tz-probes in comparison to blocking efficiencies.

Finally, the relationship between the in vivo performance of the used Tz-probes and the results obtained from the blocking assay was investigated. A strong correlation was found between the blocking effect of the unlabeled $\mathrm{Tz}$ and the $\mathrm{T} / \mathrm{M}$ ratio (Figure 3D) as well as the selective tumor uptake (tumor to tumor-control (T/Tc) ratio) (Figure S78 and Table S4) of the respective ${ }^{18} \mathrm{~F}$-labeled probes in pretargeted PET imaging studies. These significant relationships confirm the validity of the blocking assay and our finding that reduced lipophilicity and high IEDDA reactivity are key parameters for the in vivo performance of Tz-derivatives. Our results show that low lipophilicity enhances the ability of the bioorthogonal Tz-agent to bind to TCO-mAbs at the tumor site. Moreover, faster excretion of radiolabeled probes, which is crucial for obtaining high tumor-to-background ratios is also facilitated by low lipophilicity of Tz-derivatives (Figure 3). 
A
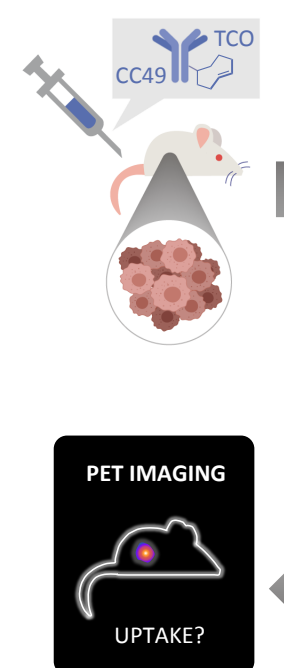

CORRELATION WITH BLOCKING?

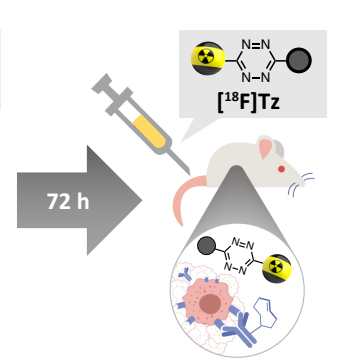

$1 \mathrm{~h}$

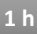

$1 \mathrm{~h}$
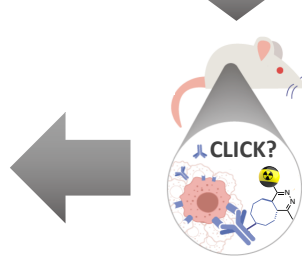

PRETARGETED in vivo LIGATION?
B

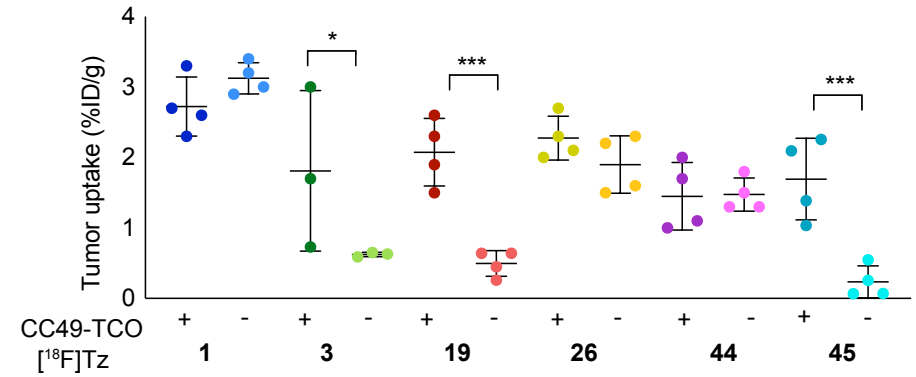

C

$\mathrm{D}$

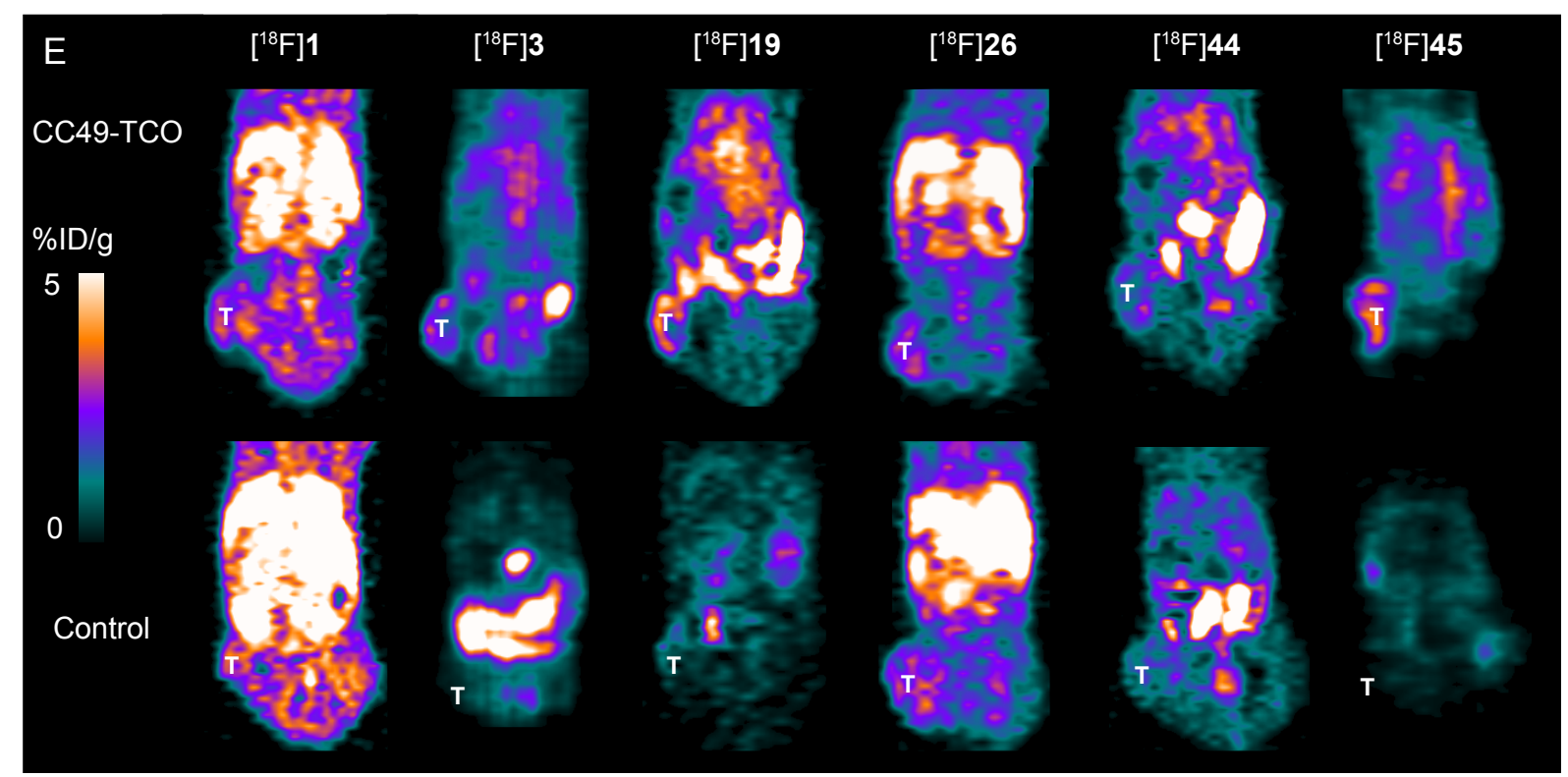

Figure 3. Pretargeted PET imaging in BALB/c nude mice bearing LS174T tumor xenografts with six ${ }^{18} \mathrm{~F}-\mathrm{labeled}$ Tz-derivatives. Animals were treated with CC49-TCO or saline (control) $72 \mathrm{~h}$ prior to injection of the radiolabeled Tz-derivative. (A) Schematic illustration of the pretargeting experiment and the research question: Is there a correlation between the blocking effect and the PET imaging contras. (B) Image-derived mean uptake values are presented as percentage of the injected dose per gram (\%ID/g) in tumor. (C) Tumor-to-muscle (T/M) ratios $\left(n=4\right.$ mice, except for $\left.\left[{ }^{18} \mathrm{~F}\right] 3, n=3\right)$. Data is represented as mean \pm S.D. $(* p<0.05$ and $* * * p<0.001)$. For all groups $n=4$ mice (except $\left[{ }^{18} \mathrm{~F}\right] 3$ where $n=3$ ) (D) Correlation between the blocking effect of the unlabeled Tz-derivatives 1, 3, 19, 26, 44, and 45 and the T/Mratios for the corresponding ${ }^{18} \mathrm{~F}$-labeled compounds observed by in vivo pretargeted PET imaging. A strong correlation was found (linear regression: $\left.\mathrm{R}^{2}=0.78, p=0.019, n=6\right)$. Data is represented as mean $\pm \mathrm{S}$. D. The asterisk indicates significant difference $(* p<0.05$ and $* * *$ $p<0.001$ ) when compared to control. (E) Representative images of PET scans $1 \mathrm{~h} \mathrm{p} . \mathrm{i}$. of the radiolabeled Tz $\left(\left[{ }^{18} \mathrm{~F}\right] \mathbf{1},\left[{ }^{18} \mathrm{~F}\right] \mathbf{3},\left[{ }^{18} \mathrm{~F}\right] \mathbf{1 9},\left[{ }^{18} \mathrm{~F}\right] \mathbf{2 6}\right.$, $\left[{ }^{18} \mathrm{~F}\right] 44$ and $\left.\left[{ }^{18} \mathrm{~F}\right] 45\right)$ in pretargeted PET imaging studies (T indicates the position of the tumor). $\left[{ }^{18} \mathrm{~F}\right] 3$, $\left[{ }^{18} \mathrm{~F}\right] 19$ and $\left[{ }^{18} \mathrm{~F}\right] 45$ displayed specific tumor uptake and the tumor is clearly visualized in the PET image.

\section{CONCLUSION}

The advancement of in vivo chemical tools based on a better understanding of the scope and limitations of bioorthogonal reactions, in vitro and in living systems, paves the way to clinical translation of pretargeting approaches for diagnostic (e.g. pretargeted imaging 
29,36,38,40-46) and therapeutic application (e.g. pretargeted radionuclide therapy ${ }^{1,16,19,20,47}$ or bioorthogonal cleavage of antibody-drug conjugates $\left.{ }^{2,17,18}\right)$. However, progress in this field is limited due to the required elaborate development of (radio)labeled compounds for in vivo evaluation, hampering the use of compound libraries for systematic studies to gain further insight. The developed blocking assay described herein tackles this challenge. By screening of 45 unlabeled Tz-derivatives, we were able to reveal the key parameters that are necessary for a $\mathrm{Tz}$ to be applied in pretargeting. High IEDDA-reactivity of the Tz-scaffold with a second-order rate constant of $>50,000 \mathrm{M}^{-1} \mathrm{~s}^{-1}$ was shown to be an important parameter to achieve efficient in vivo ligation ( $>96 \%$ blocking) to pretargeted mAb-TCO conjugates in LS174T xenografts. Unexpectedly, reduced lipophilicity was identified to play an even more decisive role, with $\operatorname{cog} D_{7.4}$ values being a strong indicator for the in vivo ligation performance of Tz-derivatives. In particular, $\operatorname{cog} D_{7.4}$ values below -3 increased the chances for successful in vivo ligation in the applied tumor model. These key findings from the blocking study were confirmed by pretargeted PET imaging. The increasing knowledge regarding the IEDDA-reactivity of various Tz-scaffolds, as well as the fact that calculated parameters (i.e. $\left.\operatorname{cog} D_{7.4}\right)$ can be used may guide and accelerate the design and development of Tz-derivatives for in vivo applications.

Overall, we present and demonstrate a new strategy and method for the systematic investigation of bioorthogonal pretargeting. The concept of our blocking assay can be translated to other tumor models and/or targets, in combination with respective mAbs as targeting vectors/carriers. We believe that the revealed key parameters enable the development of Tz-derivatives as multifunctional tools for diagnostic and therapeutic applications, ultimately to improve and accelerate the clinical translation of in vivo chemistry.

\section{ASSOCIATED CONTENT}

\section{Supporting Information}

Details on experimental procedures for organic synthesis, radiochemistry, reaction kinetics and in vivo studies are provided in the Supporting Information. All animal experiments in this study were approved by national animal welfare committees in Austria and Denmark, and the experiments were performed in accordance with European guidelines. 


\section{AUTHOR INFORMATION}

\section{Corresponding Author}

*Matthias M. Herth

Department of Drug Design and Pharmacology, University of Copenhagen

Jagtvej 160, 2100 Copenhagen Ø, Denmark

Tel: +4535336624

E-mail:matthias.herth@sund.ku.dk

*Andreas Kjaer

Department of Clinical Physiology, Nuclear Medicine \& PET, Rigshospitalet

Blegdamsvej 9, 2100 Copenhagen Ø, Denmark

Tel: +4527258614

E-mail: akjaer@sund.ku.dk

*Hannes Mikula

Institute of Applied Synthetic Chemistry, TU Wien

Getreidemarkt 9, 1060 Vienna, Austria

orcid.org/0000-0002-9218- 9722

E-mail: hannes.mikula@tuwien.ac.at

\section{Author Contributions}

${ }^{\bar{T}}$ EJLS, JTJ and CD contributed equally to the work. The experimental work was carried out through contributions of EJLS, JTJ, CD, UMB, KN, PEE, KB, VS, MW, DS, CBMP, LH, MSM, TW and RR. The study was designed by EJLS, JTJ, CD, UMB, KN, PEE, MR, JLK, $\mathrm{HM}, \mathrm{AK}$ and MMH. The manuscript was written through contributions of all authors. All authors have given approval to the final version of the manuscript.

\section{ACKNOWLEDGEMENT}

This project has received funding from the European Union's EU Framework Programme for Research and Innovation Horizon 2020, under grant agreements no. 670261 and 668532. VS was supported by BRIDGE - Translational Excellence Programme at the Faculty of Health and Medical Sciences, University of Copenhagen, funded by the Novo Nordisk Foundation (grant agreement no. NNF18SA0034956). The Lundbeck Foundation, the Novo Nordisk Foundation, the Innovation Fund Denmark, The Carlsberg Foundation (CF18-0126), the Danish Cancer Society, Arvid Nilsson Foundation, Svend Andersen Foundation, the Neye Foundation, the Research Foundation of Rigshospitalet, the Danish National Research 
Foundation (grant 126), the Research Council of the Capital Region and the Research Council for Independent Research are further acknowledged. Ida Nymann Petersen, Giorgos Kougioumtzoglou and Placid Nnamdi Orji are thanked for technical assistance.

\section{REFERENCES}

1. Steen, E. J. L.; Edem, P. E.; Norregaard, K.; Jorgensen, J. T.; Shalgunov, V.; Kjaer, A.; Herth, M. M., Pretargeting in nuclear imaging and radionuclide therapy: Improving efficacy of theranostics and nanomedicines. Biomaterials 2018, 179, 209245.

2. Rossin, R.; Versteegen, R. M.; Wu, J.; Khasanov, A.; Wessels, H. J.; Steenbergen, E. J.; Ten Hoeve, W.; Janssen, H. M.; van Onzen, A.; Hudson, P. J.; Robillard, M. S., Chemically triggered drug release from an antibody-drug conjugate leads to potent antitumour activity in mice. Nat. Commun. 2018, 9 (1), 1484.

3. Hapuarachchige, S.; Artemov, D., Theranostic Pretargeting Drug Delivery and Imaging Platforms in Cancer Precision Medicine. Front. Oncol. 2020, 10, 1131.

4. Altai, M.; Membreno, R.; Cook, B.; Tolmachev, V.; Zeglis, B. M., Pretargeted Imaging and Therapy. J. Nucl. Med. 2017, 58 (10), 1553-1559.

5. Scott, A. M.; Wolchok, J. D.; Old, L. J., Antibody therapy of cancer. Nat. Rev. Cancer. 2012, 12 (4), 278-87.

6. van Dongen, G. A.; Visser, G. W.; Lub-de Hooge, M. N.; de Vries, E. G.; Perk, L. R., Immuno-PET: a navigator in monoclonal antibody development and applications. Oncologist 2007, 12 (12), 1379-89.

7. Boswell, C. A.; Brechbiel, M. W., Development of radioimmunotherapeutic and diagnostic antibodies: an inside-out view. Nucl. Med. Biol. 2007, 34 (7), 757-78.

8. Larson, S. M.; Carrasquillo, J. A.; Cheung, N. K.; Press, O. W., Radioimmunotherapy of human tumours. Nat. Rev. Cancer. 2015, 15 (6), 347-60.

9. Borjesson, P. K.; Jauw, Y. W.; de Bree, R.; Roos, J. C.; Castelijns, J. A.; Leemans, C. R.; van Dongen, G. A.; Boellaard, R., Radiation dosimetry of ${ }^{89} \mathrm{Zr}$-labeled chimeric monoclonal antibody U36 as used for immuno-PET in head and neck cancer patients. J. Nucl. Med. 2009, 50 (11), 1828-36.

10. Dijkers, E. C.; Oude Munnink, T. H.; Kosterink, J. G.; Brouwers, A. H.; Jager, P. L.; de Jong, J. R.; van Dongen, G. A.; Schroder, C. P.; Lub-de Hooge, M. N.; de Vries, E. G., Biodistribution of ${ }^{89} \mathrm{Zr}$-trastuzumab and PET imaging of HER2-positive 
lesions in patients with metastatic breast cancer. Clin. Pharmacol. Ther. 2010, 87 (5), 586-92.

11. Reardan, D. T.; Meares, C. F.; Goodwin, D. A.; McTigue, M.; David, G. S.; Stone, M. R.; Leung, J. P.; Bartholomew, R. M.; Frincke, J. M., Antibodies against metal chelates. Nature 1985, 316 (6025), 265-8.

12. Goodwin, D. A.; Mears, C. F.; McTigue, M.; David, G. S., Monoclonal antibody hapten radiopharmaceutical delivery. Nucl. Med. Commun. 1986, 7 (8), 569-80.

13. Rossin, R.; Verkerk, P. R.; van den Bosch, S. M.; Vulders, R. C.; Verel, I.; Lub, J.; Robillard, M. S., In vivo chemistry for pretargeted tumor imaging in live mice. Angew. Chem. Int. Ed. 2010, 49 (19), 3375-8.

14. Zeglis, B. M.; Brand, C.; Abdel-Atti, D.; Carnazza, K. E.; Cook, B. E.; Carlin, S.; Reiner, T.; Lewis, J. S., Optimization of a Pretargeted Strategy for the PET Imaging of Colorectal Carcinoma via the Modulation of Radioligand Pharmacokinetics. Mol. Pharm. 2015, 12 (10), 3575-87.

15. Rossin, R.; Lappchen, T.; van den Bosch, S. M.; Laforest, R.; Robillard, M. S., Diels-Alder reaction for tumor pretargeting: in vivo chemistry can boost tumor radiation dose compared with directly labeled antibody. J. Nucl. Med. 2013, 54 (11), 1989-95.

16. Keinanen, O.; Fung, K.; Brennan, J. M.; Zia, N.; Harris, M.; van Dam, E.; Biggin, C.; Hedt, A.; Stoner, J.; Donnelly, P. S.; Lewis, J. S.; Zeglis, B. M., Harnessing $(64) \mathrm{Cu} /(67) \mathrm{Cu}$ for a theranostic approach to pretargeted radioimmunotherapy. Proc. Natl. Acad. Sci. 2020, 117 (45), 28316-27.

17. Ediriweera, G. R.; Simpson, J. D.; Fuchs, A. V.; Venkatachalam, T. K.; Van De Walle, M.; Howard, C. B.; Mahler, S. M.; Blinco, J. P.; Fletcher, N. L.; Houston, Z. H.; Bell, C. A.; Thurecht, K. J., Targeted and modular architectural polymers employing bioorthogonal chemistry for quantitative therapeutic delivery. Chem. Sci. 2020, 11 (12), 3268-80.

18. Khan, I.; Agris, P. F.; Yigit, M. V.; Royzen, M., In situ activation of a doxorubicin prodrug using imaging-capable nanoparticles. Chem. Commun. 2016, 52 (36), 617477.

19. Wilkovitsch, M.; Haider, M.; Sohr, B.; Herrmann, B.; Klubnick, J.; Weissleder, R.; Carlson, J. C. T.; Mikula, H., A Cleavable C2-Symmetric trans-Cyclooctene Enables Fast and Complete Bioorthogonal Disassembly of Molecular Probes. J. Am. Chem. Soc. 2020, 142 (45), 19132-41. 
20. Carlson, J. C. T.; Mikula, H.; Weissleder, R., Unraveling Tetrazine-Triggered Bioorthogonal Elimination Enables Chemical Tools for Ultrafast Release and Universal Cleavage. J. Am. Chem. Soc. 2018, 140 (10), 3603-12.

21. Rossin, R.; van Duijnhoven, S. M.; Ten Hoeve, W.; Janssen, H. M.; Kleijn, L. H.; Hoeben, F. J.; Versteegen, R. M.; Robillard, M. S., Triggered Drug Release from an Antibody-Drug Conjugate Using Fast "Click-to-Release" Chemistry in Mice. Bioconjugate Chem. 2016, 27 (7), 1697-706.

22. Versteegen, R. M.; Rossin, R.; ten Hoeve, W.; Janssen, H. M.; Robillard, M. S., Click to release: instantaneous doxorubicin elimination upon tetrazine ligation. Angew Chem. Int. Ed. 2013, 52 (52), 14112-6.

23. Blackman, M. L.; Royzen, M.; Fox, J. M., Tetrazine ligation: Fast bioconjugation based on inverse-electron-demand Diels-Alder reactivity. J. Am. Chem. Soc. 2008, 130 (41), 13518-9.

24. Darko, A.; Wallace, S.; Dmitrenko, O.; Machovina, M. M.; Mehl, R. A.; Chin, J. W.; Fox, J. M., Conformationally strained trans-cyclooctene with improved stability and excellent reactivity in tetrazine ligation. Chem. Sci. 2014, 5 (10), 3770-6.

25. Evans, H. L.; Nguyen, Q. D.; Carroll, L. S.; Kaliszczak, M.; Twyman, F. J.; Spivey, A. C.; Aboagye, E. O., A bioorthogonal ${ }^{68} \mathrm{Ga}$-labelling strategy for rapid in vivo imaging. Chem. Commun. 2014, 50 (67), 9557-60.

26. Zeglis, B. M.; Sevak, K. K.; Reiner, T.; Mohindra, P.; Carlin, S. D.; Zanzonico, P.; Weissleder, R.; Lewis, J. S., A Pretargeted PET Imaging Strategy Based on Bioorthogonal Diels-Alder Click Chemistry. J.Nuc.Med. 2013, 54 (8), 1389-96.

27. Rossin, R.; van den Bosch, S. M.; Ten Hoeve, W.; Carvelli, M.; Versteegen, R. M.; Lub, J.; Robillard, M. S., Highly reactive trans-cyclooctene tags with improved stability for Diels-Alder chemistry in living systems. Bioconjugate Chem. 2013, 24 (7), 1210-7.

28. Gill, H. S.; Marik, J., Preparation of ${ }^{18}$ F-labeled peptides using the copper(I)catalyzed azide-alkyne 1,3-dipolar cycloaddition. Nat. Protoc. 2011, 6 (11), 1718-25.

29. Meyer, J. P.; Adumeau, P.; Lewis, J. S.; Zeglis, B. M., Click Chemistry and Radiochemistry: The First 10 Years. Bioconjugate Chem. 2016, 27 (12), 2791-807.

30. Ross, T. L.; Honer, M.; Lam, P. Y. H.; Mindt, T. L.; Groehn, V.; Schibli, R.; Schubiger, P. A.; Ametamey, S. M., Fluorine-18 Click Radiosynthesis and Preclinical Evaluation of a New ${ }^{18} \mathrm{~F}$-Labeled Folic Acid Derivative. Bioconjugate Chem. 2008, 19 (12), 2462-70. 
31. Marik, J.; Sutcliffe, J. L., Click for PET: rapid preparation of $\left[{ }^{18} \mathrm{~F}\right]$ fluoropeptides using $\mathrm{Cu}-\mathrm{I}$ catalyzed 1,3-dipolar cycloaddition. Tetrahedron Lett. 2006, 47 (37), $6681-4$.

32. Glaser, M.; Arstad, E., "Click labeling" with 2-[ $\left[{ }^{18} \mathrm{~F}\right]$ fluoroethylazide for positron emission tomography. Bioconjugate Chem. 2007, 18 (3), 989-93.

33. Denk, C.; Wilkovitsch, M.; Skrinjar, P.; Svatunek, D.; Mairinger, S.; Kuntner, C.; Filip, T.; Frohlich, J.; Wanek, T.; Mikula, H., $\left[{ }^{18} \mathrm{~F}\right]$ Fluoroalkyl azides for rapid radiolabeling and $(\mathrm{Re})$ investigation of their potential towards in vivo click chemistry. Org. Biomol. Chem. 2017, 15 (28), 5976-82.

34. Maschauer, S.; Haubner, R.; Kuwert, T.; Prante, O., ${ }^{18}$ F-glyco-RGD peptides for PET imaging of integrin expression: efficient radiosynthesis by click chemistry and modulation of biodistribution by glycosylation. Mol. Pharm. 2014, 11 (2), 505-15.

35. Li, Z.; Cai, H.; Hassink, M.; Blackman, M. L.; Brown, R. C.; Conti, P. S.; Fox, J. M., Tetrazine-trans-cyclooctene ligation for the rapid construction of ${ }^{18} \mathrm{~F}$-labeled probes. Chem. Commun. 2010, 46 (42), 8043-5.

36. Denk, C.; Svatunek, D.; Filip, T.; Wanek, T.; Lumpi, D.; Frohlich, J.; Kuntner, C.; Mikula, H., Development of a ${ }^{18} \mathrm{~F}$-labeled tetrazine with favorable pharmacokinetics for bioorthogonal PET imaging. Angew. Chem. Int. Ed. 2014, 53 (36), 9655-9.

37. Steen, E. J. L.; Jorgensen, J. T.; Johann, K.; Norregaard, K.; Sohr, B.; Svatunek, D.; Birke, A.; Shalgunov, V.; Edem, P. E.; Rossin, R.; Seidl, C.; Schmid, F.; Robillard, M. S.; Kristensen, J. L.; Mikula, H.; Barz, M.; Kjaer, A.; Herth, M. M., Trans-Cyclooctene-Functionalized PeptoBrushes with Improved Reaction Kinetics of the Tetrazine Ligation for Pretargeted Nuclear Imaging. ACS Nano 2020, 14 (1), 56884.

38. Meyer, J. P.; Kozlowski, P.; Jackson, J.; Cunanan, K. M.; Adumeau, P.; Dilling, T. R.; Zeglis, B. M.; Lewis, J. S., Exploring Structural Parameters for Pretargeting Radioligand Optimization. J. Med. Chem. 2017, 60 (19), 8201-17.

39. Keinanen, O.; Fung, K.; Pourat, J.; Jallinoja, V.; Vivier, D.; Pillarsetty, N. K.; Airaksinen, A. J.; Lewis, J. S.; Zeglis, B. M.; Sarparanta, M., Pretargeting of internalizing trastuzumab and cetuximab with a ${ }^{18} \mathrm{~F}$-tetrazine tracer in xenograft models. EJNMMI Res. 2017, 7 (1), 95.

40. Denk, C.; Svatunek, D.; Mairinger, S.; Stanek, J.; Filip, T.; Matscheko, D.; Kuntner, C.; Wanek, T.; Mikula, H., Design, Synthesis, and Evaluation of a Low- 
Molecular-Weight ${ }^{11} \mathrm{C}$-Labeled Tetrazine for Pretargeted PET Imaging Applying Bioorthogonal in Vivo Click Chemistry. Bioconjugate Chem. 2016, 27 (7), 1707-12.

41. Edem, P. E.; Jorgensen, J. T.; Norregaard, K.; Rossin, R.; Yazdani, A.; Valliant, J. F.; Robillard, M.; Herth, M. M.; Kjaer, A., Evaluation of a ${ }^{68}$ Ga-Labeled DOTATetrazine as a PET Alternative to ${ }^{111}$ In-SPECT Pretargeted Imaging. Molecules 2020, 25 (3).

42. Steen, E. J. L.; Jorgensen, J. T.; Petersen, I. N.; Norregaard, K.; Lehel, S.; Shalgunov, V.; Birke, A.; Edem, P. E.; L'Estrade, E. T.; Hansen, H. D.; Villadsen, J.; Erlandsson, M.; Ohlsson, T.; Yazdani, A.; Valliant, J. F.; Kristensen, J. L.; Barz, M.; Knudsen, G. M.; Kjaer, A.; Herth, M. M., Improved radiosynthesis and preliminary in vivo evaluation of the ${ }^{11} \mathrm{C}$-labeled tetrazine $\left[{ }^{11} \mathrm{C}\right] \mathrm{AE}-1$ for pretargeted PET imaging. Bioorg. Med. Chem. Lett. 2019, 29 (8), 986-90.

43. Meyer, J. P.; Houghton, J. L.; Kozlowski, P.; Abdel-Atti, D.; Reiner, T.; Pillarsetty, N. V. K.; Scholz, W. W.; Zeglis, B. M.; Lewis, J. S., ${ }^{18}$ F-Based Pretargeted PET Imaging Based on Bioorthogonal Diels Alder Click Chemistry. Bioconjugate Chem. 2016, 27 (2), 298-301.

44. Edem, P. E.; Sinnes, J. P.; Pektor, S.; Bausbacher, N.; Rossin, R.; Yazdani, A.; Miederer, M.; Kjaer, A.; Valliant, J. F.; Robillard, M. S.; Rosch, F.; Herth, M. M., Evaluation of the inverse electron demand Diels-Alder reaction in rats using a ${ }^{44} \mathrm{Sc}-$ labelled tetrazine for pretargeted PET imaging. EJNMMI Res. 2019, 9.

45. Keinanen, O.; Li, X. G.; Chenna, N. K.; Lumen, D.; Ott, J.; Molthoff, C. F.; Sarparanta, M.; Helariutta, K.; Vuorinen, T.; Windhorst, A. D.; Airaksinen, A. J., A New Highly Reactive and Low Lipophilicity Fluorine-18 Labeled Tetrazine Derivative for Pretargeted PET Imaging. ACS. Med. Chem. Lett. 2016, 7 (1), 62-6.

46. Herth, M. M.; Andersen, V. L.; Lehel, S.; Madsen, J.; Knudsen, G. M.; Kristensen, J. L., Development of a ${ }^{11} \mathrm{C}$-labeled tetrazine for rapid tetrazine-trans-cyclooctene ligation. Chem. Commun. 2013, 49 (36), 3805-7.

47. Lappchen, T.; Rossin, R.; van Mourik, T. R.; Gruntz, G.; Hoeben, F. J. M.; Versteegen, R. M.; Janssen, H. M.; Lub, J.; Robillard, M. S., DOTA-tetrazine probes with modified linkers for tumor pretargeting. Nucl. Med. Biol. 2017, 55, 19-26. 